\title{
A arte de viver em tempos de pandemia
}

\author{
The art of living in pandemic times
}

DJordana da Silva Corrêa
Doutora em Educação
Universidade Federal de Pelotas - UFPel
Pelotas, RS - Brasil
jordana.ufpel@gmail.com
Deiva Afonso Oliveira
Doutora em Filosofia
Pontifícia Universidade Católica do Rio Grande do Sul - PUC-RS
Pelotas, RS - Brasil
neivaafonsooliveira@gmail.com

Resumo: O artigo utiliza o método de pesquisa bibliográfico-reflexivo para apresentar os conceitos de "arte de viver", "exercícios espirituais" e "práticas de si", trabalhados, cada um a seu modo, por Pierre Hadot (1922-2010) e Michel Foucault (1926-1984). O objetivo é apontar que, mesmo em meio aos problemas trazidos e evidenciados pela pandemia de COVID-19, é possível a transformação do indivíduo, no sentido de que, em meio ao caos, sempre deve haver esperança, de modo a modificar o olhar do sujeito em relação ao outro. Com isso, trazemos duas sessões principais: uma, que retoma o contexto da pandemia e, outra, que aponta, por meio das teorias filosóficas e dos dois referenciais, uma nova maneira de viver.

Palavras-Chave: COVID-19. Exercícios espirituais. Arte de viver.

Abstract: The article uses bibliografic-reflective research method to present the concepts of "art of living", "spiritual exercises" and "practices of self", by Pierre Hadot (1922-2010) and Michel Foucault (1926-1984). The objective is to point out that, even in the midst of the problems brought about and evidenced by COVID-19 pandemic, it is possible to modify individuals and to make them look at other people with the sense that in the midst of chaos there must always be hope. We bring two main sections: first, we take up the pandemic context; and, secondly, the text points out through philosophical theories the references which rebound a new way of living.

Key-Words: COVID-19. Spiritual exercises. Art of living. 


\section{Introdução}

A pandemia de COVID-19 modificou o modo de pensar de várias pessoas, levando-as a refletir sobre a vida. Pensar criticamente a respeito do que estamos vivendo auxilia-nos a ter percepções mais claras sobre nossas atuais vivências, bem como de vivências anteriores. Trazer à luz alguns filósofos pode contribuir no esclarecimento do que ocorre conosco, auxiliando-nos a refletir sobre esse novo momento como novas possibilidades de vida e de pensamento em meio a um tempo de desespero e desilusão.

Pierre Hadot (1922-2010) e Michel Foucault (1926-1984) refletem, complementarmente, sobre exercícios espirituais, ou seja, movimentos em busca de transformação, trazendo uma abordagem sobre cuidar de si mesmo através de práticas de si. Tais conceitos intercruzam-se, pelo fato de levar o indivíduo a uma metamorfose - uma arte de viver, uma estética da existência. Os filósofos foram contemporâneos entre si e, muito embora tivessem uma ligação teórica a respeito do tema, não lhes foi possível um diálogo muito extenso, devido à morte de Foucault. Foucault foi leitor atento de Hadot, e embora Hadot reconheça algumas divergências entre suas ideias, muitas convergências também são citadas.

E, então, pergunta-se: por que falar na arte de viver e em exercícios espirituais em meio ao caos de uma pandemia, em meio ao desespero de indivíduos que enfrentam uma dura realidade? Uma das respostas é porque o caos pode gerar movimento, pode instigar o indivíduo a buscar aquilo que lhe falta. E não há momento mais necessários do este que estamos atravessando, para trazermos à reflexão possibilidades de o indivíduo propiciar equilíbrio e serenidade para si e para os que estão próximos dele e, na sequência, seguir em frente, como um modo de esperança.

\section{O tempo pandêmico: temerosidades e novas formas de vida}

O ano de 2019 foi encerrado com algumas notícias a respeito de certo vírus que assolava o país da China, mais precisamente em dezembro de 2019, na cidade de Wuhan. Já naquela época, fora batizado de "Coronavírus". Em meio a trocas de acusações entre alguns países em busca de culpados, o vírus acabou se alastrando por toda a China e, mais tarde, por países da Ásia, Europa e Américas.

A ocasião era urgente, temerosa, dolorida: pessoas adoecendo rapidamente, mortes aumentando a cada dia. Diante de tal realidade, foram necessárias ações extremas de todos os governos, a fim de que a catástrofe fosse minimizada, com lockdown em algumas cidades de vários países. A realidade no Brasil, entre janeiro e fevereiro de 2020, ainda era de esperanças pelo novo ano, férias e Carnaval. Torcíamos, verdadeiramente, para que a pandemia não nos alcançasse, afinal, 
ela ainda nos parecia longínqua, até que houve a confirmação do primeiro caso brasileiro, em 26 de fevereiro de 2020.

As cidades brasileiras inicialmente mais afetadas foram São Paulo-SP, Rio de Janeiro-RJ e Manaus-AM, em decorrência de seu intenso trânsito aéreo, além do período de festas de final/início de ano. Hoje, estamos com mais de 130 mil mortes por COVID-19 e quase 4,5 milhões de infectados, com uma grande maioria já recuperados.

Com a COVID-19, novas realidades foram apresentadas às pessoas em nosso país: escolas e universidades foram fechadas por risco de contágio, empresas suspenderam contratos de trabalhadores para minimizar seus prejuízos, outras demitiram pessoal e muitas, ainda, fecharam suas portas. Os trabalhadores de serviços essenciais (médicos, enfermeiros, ramos farmacêutico e alimentício) foram assimilando a urgência de vários cuidados, uma vez que não paralisaram suas atividades.

Ainda vivemos tempos temerosos para aqueles que precisam encontrar um trabalho para sua subsistência, para estudantes na expectativa de concluir seus estudos ou ainda dar continuidade a eles, seja realizando ENCCEJA, ENEM ou PAVE. Além disso, pais e mães que precisam trabalhar e não têm onde deixar os filhos, pois as escolas de educação infantil estão fechadas, tendo que, a duras penas, conciliar família e atividades profissionais.

Profissionais de vários ramos precisaram readequar sua rotina e criar novas formas de trabalhar e de viver: o trabalho remoto. E-mails, celulares, conferências online nunca foram tão utilizadas para esse fim; professores produzindo vídeos e materiais para aulas a distância; aulas online. Enfim, foi preciso que nos readequássemos, adaptando nossas rotinas para que não ficássemos vinte e quatro horas por dia em frente aos aparelhos eletrônicos, escasseando horas de descanso e lazer e por termos excedido o tempo diário de trabalho.

Como se não bastasse, a sensação de medo paira sobre as pessoas: o medo da contaminação, o temor de ficar doente e sentir os sintomas dolorosos da doença e ainda de perder um ente querido. Ao mesmo tempo, existem aqueles que ainda negam a periculosidade do vírus a falta de empatia desses "corajosos" é desumana, fazendo-nos pensar se, ao menos, se importam consigo mesmos. Talvez algumas ações sejam exageradas, porém precisamos nos cuidar e cuidar do próximo, na medida do possível.

A pandemia trouxe-nos novos modos de viver, de trabalhar, de estudar, de perceber o outro e, principalmente, novas maneiras de estar próximos do outro. Acima de tudo, propiciou novos jeitos de percebermos a nós mesmos, com a possibilidade de fazer, em meio ao caos, uma arte de existir e de viver. 


\section{O cuidado de si e exercícios espirituais}

Vivemos uma situação distópica, mas precisamos fazer desse momento caótico um momento de esperanças. Uma esperança que, de acordo com Paulo Freire, não deriva de "esperar".

É preciso ter esperança, mas ter esperança do verbo esperançar; porque tem gente que tem esperança do verbo esperar. E esperança do verbo esperar não é esperança, é espera. Esperançar é se levantar, esperançar é ir atrás, esperançar é construir, esperançar é não desistir! Esperançar é levar adiante, esperançar é juntar-se com outros para fazer de outro modo... (Paulo Freire, s/d).

Apesar dessa situação muito difícil vivida por todos - seja sem emprego, seja longe da família e dos amigos, seja doente ou por ter perdido alguém próximo -, é necessário que sigamos adiante, preferencialmente com o auxílio de outrem, mesmo que de modo online, porque assim se dividem as dores e também as alegrias. Mas, que não desistamos de lutar.

Michel Foucault já nos explicou a respeito da amizade e da importância do próximo em nossas vidas. Percebemos que o sujeito não está só e que não é um ser que vive isoladamente, uma vez que é sociável e deve relacionar-se com seus pares: “[...] é preciso considerar-se como um ser social nascido para a comunidade. Enfim, saber que o mundo é um habitat comum, onde todos os homens estão reunidos para justamente constituir essa comunidade” (FOUCAULT, 2010, p. 210).

Um dos modos de evitar que o sujeito fique sozinho e se relacione com o outro, seja por interesses similares ou por vínculo afetivo, chamamos de amizade. A amizade é, “em geral, a comunhão entre duas ou mais pessoas ligadas por atitudes concordantes e por afetos positivos [...] A amizade é, certamente, uma comunhão no sentido de que o amigo se comporta em relação ao amigo como em relação a si mesmo" (ABBAGNANO, 2012, p. 37). Michel Montaigne (15331592), no Ensaio denominado "Da Amizade”, já enfatizara o caráter necessário da reciprocidade.

A amizade seria, então, essa reciprocidade de um com o outro, uma diretiva a viver considerando o próximo como um outro “eu”. Em Ética a Nicômaco, Aristóteles também se refere à amizade, com relação a três pontos principais: “[...] no tocante aos amigos, porém, diz-se que devemos desejar-lhes o bem no interesse deles próprios. Mas aos que desejam bem dessa forma só atribuímos benevolência, se o desejo não é recíproco; a benevolência, quando recíproca, torna-se amizade" (ARISTÓTELES, 1991, p. 170). O filósofo destaca que a amizade aproxima-se da benevolência, de modo que um indivíduo possui afeto, simpatia e boa vontade para com o próximo, mesmo que os interesses e desejos sejam apenas de um. Porém, Aristóteles também diferencia a amizade do amor, uma vez que são próximos, mas não são o mesmo sentimento: 
[...] portanto, é em espécie que diferem também as correspondentes formas de amor e de amizade. Há, assim, três espécies de amizade, iguais em número às coisas que são estimáveis; pois com respeito a cada uma delas existe um amor mútuo e conhecido, e os que se amam desejam-se bem a respeito daquilo por que se amam (ARISTÓTELES, 1991, p. 18).

Assim, vemos que, ao falar da amizade, Aristóteles destaca a necessidade da reciprocidade e da relação de um sujeito com o outro, uma viagem para sair do interior de si e compreender o outro, conhecendo e aprendendo a singularidade de cada indivíduo, uma vez que estamos imbricados uns com os outros.

Essas relações fazem com que os problemas tornem-se cargas mais leves para serem carregados, pois divide-se com o outro os medos, agonias e, nesse momento de novas descobertas de relacionamento uns com os outros, apelidado popularmente de "novo normal", é que se torna mais importante a empatia e o compartilhamento de experiências.

A amizade é uma afinidade coletiva, vincula-se a uma relação de cortesia de um indivíduo com o outro, reverbera situações de troca e, por isso, é considerada um quadro relacional, cuja interação com o outro apresenta-se, para Foucault, como indispensável para uma relação consigo mesmo.

O papel do outro é indispensável para a produção de um esboço de si compreensível. Este pensamento constitui uma constante de toda a tradição greco-romana. Portanto, Foucault não reivindica nas suas análises uma autoconstituição isolada que exclua qualquer relacionamento com o outro, mas para ele o outro está sempre presente na origem da constituição estética de si, na figura do mestre, guia, professor, diretor de consciência ou amigo (ORTEGA, 1999, p. 133).

Não importa a figura que auxiliará na constituição do indivíduo. Seja o mestre, o guia, o professor, um membro da família ou um amigo, Foucault considera indispensável o outro para o direcionamento do sujeito na construção de um modo de vida e, consequentemente, tornar sua vida uma obra de arte: a estética da existência.

Todo homem que tem realmente cuidado de si deve fazer amigos. Esses amigos chegam
ocasionalmente no interior da rede de trocas sociais e da utilidade. A utilidade, que é
ocasião de amizade, não deve ser abolida. É preciso mantê-la até o fim. Mas o que dará
função à utilidade no interior da felicidade é a confiança que dedicamos aos nossos
amigos que são, para conosco, capazes de reciprocidade [...] Vemos que a amizade é
inteiramente da ordem do cuidado de si e que é pelo cuidado de si que se deve ter amigos
(FOUCAULT, 2010, p. 176).

Quando se refere ao sujeito, Foucault expõe que temos a opção de seguir sozinhos ou na companhia de outros, mas considera a amizade de fundamental importância para a constituição do indivíduo, tornando-se incompleto um cuidado de si sem a presença e a reciprocidade do outro.

O que seria esse cuidado de si, para Foucault? N'A Hermenêutica do Sujeito (2010), o filósofo destaca algumas hipóteses, de forma que retoma o termo desde os gregos com a expressão 
epiméleia heautoû, traduzida como "cuidado de si". O pensador considera importante apreender diversos sentidos dessa expressão.

\begin{abstract}
Primeiramente, o tema de uma atitude geral, um certo modo de encarar as coisas, de estar no mundo, de praticar ações, de ter relações com o outro. A epiméleia heautoû é uma atitude - para consigo, para com os outros, para com o mundo. Em segundo lugar, a epiméleia beautoû é também uma certa forma de atenção, de olhar. Cuidar de si mesmo implica que se converta o olhar, que se conduza do exterior, [...] dos outros, do mundo, para "si mesmo". O cuidado de si implica uma certa maneira de estar atento ao que se pensa e ao que se passa no pensamento [...] Em terceiro lugar, [...]. Também designa sempre algumas ações, ações que são exercidas de si para consigo, ações pelas quais nos assumimos, nos modificamos, nos purificamos, nos transformamos e nos transfiguramos [...] (FOUCAULT, 2010, p. 11-12)
\end{abstract}

O cuidado de si mesmo pode significar o relacionamento de si com o outro; ações que podem provocar transformações no indivíduo; um olhar do exterior para o interior, olhar para si mesmo, enxergar-se, estar atento aos próprios pensamentos e se autocompreender. O cuidado de si "designa precisamente o conjunto das condições de espiritualidade, o conjunto das transformações de si que constituem a condição necessária para que se possa ter acesso à verdade" (FOUCAULT, 2010, p. 17).

Assim, podemos entender que o termo cuidado de si está relacionado à ação do sujeito com ele mesmo. Em outras palavras, "corresponde a uma ética em que o sujeito direciona suas atitudes sobre si mesmo" (GALVÃO, 2014, p. 159). Da mesma forma, Frédéric Gros (2008) expõe que o cuidado de si “constitui tanto mais um sujeito da ação, quanto um dos seus eixos essenciais consiste em estabelecer uma correspondência regrada entre os atos e as palavras. Eis aí um dos pontos importantes sublinhados por Foucault” (GROS, In.: RAGO, M.; VEIGA-NETO, A., 2008, p. 133134).

Para Gros (2008), o cuidado de si está relacionado ao modo como o sujeito se enxerga como agente de suas próprias ações, as quais podem relacionar-se, posteriormente, com o que o agente fala, ou seja, as palavras devem ser como um reflexo daquilo que faz. Essa relação entre como se age e o que se fala é o que chamamos ética, conforme Foucault, o éthos, uma maneira de ser e de se conduzir.

E esta maneira se traduz nos hábitos, maneira de se portar, caminhar; maneira de encarar os acontecimentos da vida (Foucault, 1994b, p. 714). Assim, a vida ética fazia parte de um longo processo de aprimoramento e lapidação do próprio eu, que Foucault chama de technè tou biou. Não se nascia um indivíduo ético, mas tornava-se ético à medida que se incorporavam certas práticas através do hábito cotidiano e gradativo (PELLIZZARO, 2015, p. 118).

Essas práticas que se incorporam ao cotidiano são denominadas por Foucault "técnicas de si”, ou "práticas de si”, que são exercícios, os quais o indivíduo realiza sozinho ou com outros, a fim de se transformar. 
[Técnicas de si ou práticas de si] permitem aos indivíduos efetuarem, sozinhos ou com a ajuda de outros, um certo número de operações sobre os corpos e suas almas, seus pensamentos, suas condutas, seus modos de ser; de transformarem-se a fim de atender um certo estado de felicidade, de pureza, de sabedoria, de perfeição ou de imortalidade (FOUCAULT, 1994, p.785, grifo nosso).

Assim, os exercícios chamados "práticas de si” permitem a transformação do sujeito e essa modificação interior pode refletir em suas ações.

Por uma outra vertente, Pierre Hadot (1922-2010) refere-se a esses exercícios, como exercícios espirituais, os quais o autor considera um dos três elementos essenciais de sua visão da filosofia. O primeiro movimento do autor em seu livro Exercícios Espirituais e Filosofia Antiga (2014) é explicar o motivo do uso do termo "espirituais", e não "psíquico", "ético" ou "de pensamento". Eis que argumenta que

esses exercícios - nós o entrevemos pelo texto de G. Friedmann - correspondem a uma transformação da visão de mundo e a uma metamorfose da personalidade. A palavra "espiritual” permite entender bem que esses exercícios são obra não somente do pensamento, mas de todo o psiquismo do indivíduo e, sobretudo, ela revela as verdadeiras dimensões desses exercícios: graças a eles, o indivíduo se eleva à vida do Espírito objetivo, isto é, recoloca-se na perspectiva do Todo ("Eternizar-se ultrapassando-se") (HADOT, 2014, p. 20)

Os exercícios espirituais podem ser entendidos como uma transformação na maneira de ver e de ser do indivíduo, o qual pode ser extremamente custoso, pois para algumas pessoas é muito difícil olhar-se internamente e aceitar a si mesmo e/ou seus erros, admitindo a necessidade de mudança e a coragem para olhar suas dores internas, para que, pouco a pouco, essa renovação ocorra de um modo tranquilo e pouco traumático. De certa maneira, alguma modificação já ocorreu nesses momentos pandêmicos, mesmo que não tenhamos notado ou que não queiramos observar, de tal modo que conseguimos nos reinventar para o trabalho, para a família e para nós mesmos.

Pierre Hadot destaca quatro tipos de exercícios espirituais: aprender a viver, aprender a dialogar, aprender a morrer e aprender a ler. No primeiro aprendizado, o autor destaca as escolas helenísticas e romanas como exemplos, de modo que os estoicos consideram a filosofia como um exercício.

(...) a filosofia não consiste no ensino de uma teoria abstrata, ainda menos na exegese de
textos, mas numa arte de viver, numa atitude concreta, num estilo de vida determinado,
que engloba toda a existência. O ato filosófico não se situa somente na ordem do
conhecimento, mas na ordem do "eu" e do ser: é um progresso que nos faz ser mais, que
nos torna melhores. É uma conversão que subverte toda a vida, que muda o ser daquele
que a realiza. (HADOT, 2014, p. 22).

Hadot (2014) expõe que, para todas as escolas filosóficas, o principal motivo de desequilíbrio são as paixões. A filosofia aparece como uma terapêutica, de modo que educa a respeito do mal moral e do bem moral e que, excetuando-se as ocasiões incontroláveis, o indivíduo é livre para optar por seu caminho. Mais tarde, o autor lista os exercícios espirituais estoicos: a 
atenção, as meditações e "lembranças do que é bom", exercícios intelectuais, como audição, leitura e pesquisa, e, enfim, o domínio de si, a realização dos deveres e a indiferença às coisas indiferentes.

A partir disso, observa-se que tanto para os estoicos quanto para os epicuristas, a filosofia é uma terapêutica, "nossa única ocupação deve ser nossa cura. Dessa vez, porém, a cura consistirá em conduzir a alma das preocupações da vida à simples alegria de existir” (HADOT, 2014, p. 31). Há uma única diferença: para os estoicos, o exercício de aprender a viver é útil para deixar a alma tensa e alerta, um constante despertar da consciência moral; aos epicuristas, um caminho para a descontração e serenidade.

Por último, destaca-se que para os epicuristas o prazer seria um exercício espiritual e a amizade está contida nesse prazer: cada um deve tender a criar a atmosfera na qual floresce o coração. Tratava-se, antes de tudo, de ser feliz - a afeição mútua, a confiança com a qual um se apoiava no outro, contribuía mais do que tudo para a felicidade.

É então que especificamos o exercício de aprender a dialogar, de modo que entendamos a importância do diálogo com o outro, a fim de sermos capazes de também dialogarmos conosco próprios, algo muito apreciado por Sócrates e seus discípulos, uma vez que Sócrates, em seus diálogos, intencionava convidar seus ouvintes para fazer um autoexame de consciência e cuidar do seu interior. "O diálogo socrático aparece assim, portanto, como um exercício espiritual praticado em comum, que convida ao exercício espiritual interior, isto é, ao exame de consciência, à atenção a si, em síntese, ao famoso 'conhece-te a ti mesmo"' (HADOT, 2014, p. 38).

Entendemos, assim, que o exercício espiritual vai além do diálogo e da empatia com o outro, mas também consigo mesmo, num constante olhar para o próprio interior, tentando compreender a si mesmo e o porquê do seu modo de ser, agir e reagir: "É o que se passa em todo exercício espiritual; é preciso fazer a si mesmo mudar de ponto de vista, de atitude, de convicção; portanto, dialogar consigo mesmo; portanto, lutar consigo mesmo" (HADOT, 2014, p. 41).

Com todo esse momento caótico vivido com a pandemia, muito embora já estivéssemos há longa data em um grau de caos social e econômico, torna-se ainda mais importante um diálogo interior, um olhar para si mesmo, para compreendermos não apenas aquilo que nos aflige, mas também buscar respostas, pois elas se encontram dentro de nós. Junto ao nosso "novo normal", que se traduz por conectividade e empatia relacional, teremos que arcar com uma responsabilidade partilhada e solidariedade global. Estamos aprendendo a nos comportar de modo diferente diante dessa complexa realidade trazida pela situação de pandemia.

Nesse momento da História Mundial, algumas pessoas já iniciaram esse processo, uma vez que foi registrado um aumento da procura por exercícios de meditação e de outras terapias 
integrativas, conforme notícia veiculada no site da Uol, intitulada "Terapia alternativa ajuda no stress dapandemia”, em 18 de julho de 2020. Um terapeuta pode, certamente, auxiliar nesse processo: você precisa compartilhar suas angústias e medos; é ele quem vai lhe ensinar a olhar para o seu interior, mas apenas você descobre a si mesmo e se transforma ao se autoconhecer e autocuidar-se.

Quando você se encoraja para olhar para si mesmo e, nesse movimento de aprendizado, compreende seus pensamentos e ações para uma transformação de si com o objetivo de adquirir mais paz interior e resiliência, ou seja, um trabalho sobre si mesmo, é que você começa a olhar para (e pelo) próximo e aquilo que há a sua volta no Universo, com menos individualidade e mais universalidade de pensamento no Todo, para que todos trilhem um mesmo caminho. Esse movimento, de acordo com Hadot (2014), seria o “aprender a morrer”. Ele explica:

De fato, apreender-se-á melhor esse exercício espiritual compreendendo-o como um esforço para se libertar do ponto de vista parcial e passional, ligado ao corpo e aos sentidos, e para se elevar ao ponto de vista universal e normativo do pensamento, para se submeter às exigências do Logos e à norma do Bem. Exercitar-se para a morte é exercitar-se para a morte de sua individualidade, de suas paixões, para ver as coisas na perspectiva da universalidade e da objetividade (HADOT, 2014, p. 45).

Para Hadot (2014), o indivíduo deve libertar-se de sua individualidade em prol de um Todo, ou seja, do Universal, em certa medida deixando a subjetividade individual e passional e erguendose em direção a uma grandeza de alma, que é imaterial e imortal.

O último exercício espiritual citado por Hadot é "aprender a ler", no sentido de que as teorias filosóficas são um objeto para os exercícios espirituais, defendendo que "a vida filosófica é um desenraizamento da vida cotidiana: ela é uma conversão, uma mudança total de visão, de estilo de vida, de comportamento" (HADOT, 2014, p. 58).

Todas as teorias surgem de uma escola filosófica, na medida em que um mestre forma um discípulo e o conduz para a transformação e realização de si. Essas obras filosóficas refletem sobre, dentre outros temas, preocupações sociais, pedagógicas e metodológicas. O importante é sempre retomar essas teorias e vivê-las, refazer a experiência que ofertam, retomar a tarefa, aprender a ler, relê-las. Hadot (2014) defende que precisamos deixar que os textos falem a nós, que deixemos de lado nossas buscas por sutileza e originalidade e que nos libertemos de nossas preocupações, meditemos e "ruminemos", pois seria um dos exercícios mais difíceis. Como diz Goethe, "as pessoas não sabem quanto custa em tempo e esforço aprender a ler. Precisei de oitenta anos para tanto e sequer sou capaz de dizer se tive sucesso" (GOETHE, 1830). Constata-se, portanto, que a leitura traz muito mais que conhecimento, é uma atividade de formação e de transformação.

Hadot (2014) destaca esses novos aprendizados em uma visão filosófica, de modo que nos faz transportá-los para o (novo) meio educacional, cada um em seu ambiente particular, geralmente um cômodo de sua casa, em novos modos de se relacionar e de aprender. Então, como ensinar 
e/ou aprender a viver, a dialogar, a morrer e a ler no ambiente online? É a educação sendo reinventada.

\section{A educação online em tempos de distanciamento social}

A área da Educação foi uma das mais afetadas nesse período de distanciamento social. Aulas presenciais suspensas, crianças sem escolas enquanto os pais precisam trabalhar, não tendo com quem contar para cuidá-las; adolescentes e jovens ansiosos devido à finalização incerta do ano letivo e, consequentemente, incerteza de participar em processos seletivos como ENEM, ENCCEJA ou PAVE. O que para alguns está disponível é um ensino remoto precário devido à falta de condições financeiras para arcar com despesas de internet. Outros, ainda, alunos de escolas particulares, precisando reinventar-se no sentido de um novo modo de aprender e de uma redução brusca na carga horária de aulas. Então, desse lado, temos os discentes.

De outro lado, os professores, ansiosos com novos modos de ensinar, passar tarefas, produzir vídeos e mais a sobrecarga de reuniões e repensar a preparação de aulas. Ao fim e ao cabo, todos os elementos que fazem parte da Educação precisaram se reinventar, desde os pais e familiares que precisaram alterar suas rotinas, até as escolas. Alternativas foram sendo pensadas a fim de atender os alunos sem condições financeiras para despesas com internet ou para adquirir um computador, como busca e entrega de trabalhos e atividades impressas na escola - uma ação paliativa para reduzir, ainda que seja um mínimo, a diferença de ensino de uns para outros. Enquanto isso, outra parcela de alunos assistindo aulas síncronas, via Youtube, via plataforma da própria escola, via plataformas de Universidades; ou ainda, plataformas de atividades, como o Google Classroom, plataforma gratuita para as escolas, delivery de materiais impressos para os estudantes que não têm acesso às tecnologias.

Os problemas encontrados nesse período estão longe de serem resolvidos, principalmente no que tange aos ensinos infantil, fundamental e médio, colocando em xeque a longa caminhada para se pensar em uma educação on-line/domiciliar de qualidade. Porém, os problemas foram amenizados na medida em que houve amplo esforço, tanto de docentes quanto de pais e alunos, reduzindo os prejuízos de todos os lados.

Em relação ao ensino superior, algumas Universidades, a exemplo da Universidade Federal de Pelotas (UFPel/RS), passaram a oferecer a seus alunos disciplinas possíveis de serem ministradas de forma remota. Seu calendário presencial foi suspenso, mas algumas atividades a distância foram pensadas para que se reduzissem os prejuízos de alunos em relação a seu tempo de permanência na Universidade. Isso significa também o stress e a ansiedade permeando docentes 
ainda não tão familiarizados com as questões tecnológicas, além da alta carga de produção de materiais para as suas turmas. Por outro lado, temos a ansiedade de alunos perante a incerteza de conclusão dos cursos em tempo regular, uma vez que algumas atividades práticas foram suspensas, tais como estágios e atividades em laboratório.

O fato é que muito precisou ser adaptado e repensado. Novas maneiras de assistir/ministrar aulas foram instauradas. Até mesmo uma nova forma de "matar aula", com vídeo e microfone fechados. Que tal começarmos também a refletir sobre o bem-estar de todos esses indivíduos envolvidos? Através de Hadot (2014) e seus aprendizados, trazemos algumas reflexões.

Por primeiro, e o mais urgente, levar a esses indivíduos uma nova maneira de viver, possibilitando um olhar para seu interior, para aquilo que estão sentindo, ressignificando suas experiências, seja através de meditação ou outras atividades que auxiliam nesse processo, como terapias, yoga e afins; atividades que podem ser pensadas em formatos online via projetos de extensão de universidades, estreitando laços com a comunidade.

A transformação interior do indivíduo possui potencial de fazer com que este se preocupe com o outro e o conduza a ter empatia por ele. Por um momento, o indivíduo "morre" para si mesmo, após se autoconhecer, para ajudar a resgatar o outro em uma tentativa de auxílio, aproximando-se dele e dialogando, num processo de amizade e empatia.

Por último, não menos importante, mas para resumirmos nossa ideia, uma vez que um artigo possui espaço limitado: mais do que nunca, nossos alunos precisam da filosofia para aprender a ler, no sentido de nos aproximarmos dela como uma maneira de viver, desenraizando-nos da vida cotidiana, mudando nossa visão de mundo, de comportamento, retomando aquilo que passou a ser experiência, libertando-nos de nossas preocupações, trazendo um significado para esse novo viver.

\section{Considerações finais}

A pandemia de COVID-19 fez com que o mundo todo se adequasse a uma nova realidade: para alguns, um choque de realidade, para outros, um novo modo de viver. Para além de todas as dificuldades econômicas e sociais já existentes há algum tempo, o vírus piorou a vida de algumas pessoas, no sentido de agravar um cenário que já desenhava circunstâncias de desemprego, falta de renda, precarização das questões ligadas à saúde pública, evidenciando os problemas sanitários, principalmente nas classes mais baixas, onde água e sabão não são tão comuns como se pode pensar, ainda mais quando mal se tem o que comer. 
Outra questão levantada foi a adequação da vida aos meios tecnológicos. Algumas coisas foram ajustadas para que as pessoas, tendo a opção, evitassem sair de suas casas, inclusive para trabalhar, gerando uma adaptação e readequação nas rotinas familiares, uma vez que as escolas foram as primeiras a ter suas atividades paralisadas, fazendo com que crianças e adolescentes também permanecessem em casa.

A visão do tempo também foi modificada, uma vez que, para alguns, os dias passaram a ser todos iguais; para outros, o tempo tornou-se mais lento, pela falta de convívio com outras pessoas e pela rotina; para outros, ainda, o tempo acelerou, pois não há mais espaço para o lazer - as atividades ocuparam vinte e quatro horas e a relação da casa e do conforto do lar como um local de descanso, toma um outro significado.

Além de tudo isso, a relação entre escola e aluno também foi modificada. Novas formas de ensinar e de aprender deram um novo significado para a educação e as experiências formativas. Por esses motivos, vemos como importante discutir o tema do indivíduo aprender a olhar para o seu interior, ressignificando suas lutas, dores e até mesmo alegrias, vindo a transformar-se enquanto indivíduo e auxiliando o próximo a fazer o mesmo, mostrando a ele que não está sozinho.

O modo de viver e o relacionamento com o outro são ações que transformam o sujeito, vindo a aprimorá-lo. A formação do indivíduo é constante, constrói-se a cada dia, como uma escultura sendo moldada e tomando uma forma final. As atitudes pessoais fazem parte desse processo de formação, em direção a uma tarefa infinita de alcançar o maior grau possível de virtudes e evolução, como movimento de infinito transformar-se, uma eterna busca de melhoria, não apenas para a construção de si, mas também do outro.

A transformação do indivíduo influencia o modo como este construirá e lapidará sua vida, um trabalho constante de criação e de trabalho sobre si mesmo, com liberdade e autonomia em suas ações, construindo sua vida de modo "belo", de maneira estética. Trata-se de um jeito estético de arquitetar a própria vida, seu modo de ser, estar e existir no mundo, uma arte de viver.

As reflexões de Foucault e Hadot trazidas neste artigo são apenas para lembrar-nos que sempre existe um caminho e que o aprender a viver, o aprender a dialogar, o aprender a morrer e o aprender a ler podem ser o início de um “esperançar", como diria Paulo Freire. Seguir em frente, não desistir, pois novos tempos virão. Seremos sujeitos um pouco melhores com toda essa transformação interior.

\section{Referências}

ABBAGNANO, Nicola. Dicionário de Filosofia. 6. ed. São Paulo: Editora WMF Martins Fontes, 2012. 
ARISTÓTELES. Ética a Nicômaco. 4. ed. Trad. Leonel Vallandro e Gerd Bornheim. São Paulo: Nova Cultural, 1991.

FOUCAULT, Michel. Les techniques de soi. In: FOUCAULT, Michel. Dits et Écrits IV. Paris, Gallimard, 1994. p. 783-813.

FOUCAULT, Michel. A Hermenêutica do Sujeito: curso dado no Collège de France. 3. ed. Trad. Márcio Alves da Fonseca. São Paulo: WMF Martins Fontes, 2010.

GALVÃO, Bruno Abílio. A ética em Michel Foucault: do cuidado de si à estética da existência. Intuitio PUC-RS, Porto Alegre, v. 7, n. 1, p. 157-168, 2014. Disponível em https://revistaseletronicas.pucrs.br/ojs/index.php/intuitio/article/view/17068/11428. Acesso em 08 maio de 2019.

GROS, Frédéric. O Cuidado de Si em Michel Foucault. In: RAGO, Margareth; VEIGA-NETO, Alfredo (Orgs.). Figuras de Foucault. 2. ed. Belo Horizonte: Autêntica, 2008. pp. 127-138.

HADOT, Pierre. Exercícios Espirituais e Filosofia Antiga. São Paulo: É Realizações, 2014.

ORTEGA, Francisco. Amizade e Estética da Existência em Foucault. Rio de Janeiro: Edições Graal Ltda., 1999.

PELLIZARO, Nilmar. A amizade na perspectiva de M. Foucault. Argumentos, Fortaleza, ano 7, n. 14, p. 113-126, jul-dez 2015.

Recebido em: 28 set. 2020/ Aprovado em: 13 nov. 2020

Cite como

(ABNT NBR 6023:2018)

CORREAA, Jordana da Silva; OLIVEIRA, Neiva Afonso. A arte de viver em tempos de pandemia. Dialogia, São Paulo, n. 36, p. 149-161, set./dez. 2020. Disponível em: https://doi.org/10.5585/dialogia.n36.18288.

\section{American Psychological Association (APA)}

Corrêa, J. S., \& Oliveira, N. A. (2020, set./dez.). A arte de viver em tempos de pandemia. Dialogia, São Paulo, n. 36, p. 149-161. https://doi.org/10.5585/dialogia.n36.18288. 